Path. Microbiol. 1974;40:199

\title{
La stomatite papuleuse chez les bovins
}

\begin{tabular}{|l|l|l|}
\hline Ph. & & Dunant \\
\hline P. & & Perroud \\
\hline F. & Steck \\
\hline
\end{tabular}

Adresse de l'auteur: Ph. Dunant, Vet.-Bakteriologisches und Parasitologisch.es Institut, Abt. für Virologie der Universität Bern, CH-3001 Berne (Suisse)

L'isolation du virus est relativement facile sur culture de testicules de veaux. Bien que le cours bénin de la maladie ne justifie pas en soi un diagnostic celui-ci se révèle utile lors de suspicion de fièvre aphteuse comme diagnostic différentiel. La demonstration directe du virus au microscope électronique par contraste négatif à partir de biopsie s'est révelé un diagnostic rapide et sûr: 98,5\% des biopsies prélevées sur des lesions de stomatite papuleuse ont donné des résultats positifs. Le virus étudié sur culture de cellules embryonales de reins de veaux montre une morpho-logie et une morphogénèse typique d'un virus du groupe Paravaccinia. Maladie bénigne du veau répandue dans le monde entier, la stomatite papuleuse est caracterisee par des ulcerations sur la peau du museau et les muqueuses de la bouche. Ces lesions créent une ballonisation des cellules épithéliales de la couche granulée, principalement. Elles croissent circulairement avec guérison rapide du point d'infection. Cette zone cen-trale régénérée semble résistante à une reinfection. Le pourcentage de veaux atteints observe aux abattoirs est de 1-2\%. Ce pourcentage dans des exploitations d'engraissement est de 10-15\%. Sur un alpage, il a été observe un pourcentage plus élevé; par contre, Гannée d'après, cet alpage était libre de stomatite papuleuse. 